\title{
The complex origin of modern humans
}

\section{BOOK TITLE:}

Human origins: How diet, climate and landscape shaped us

\section{BOOK COVER:}

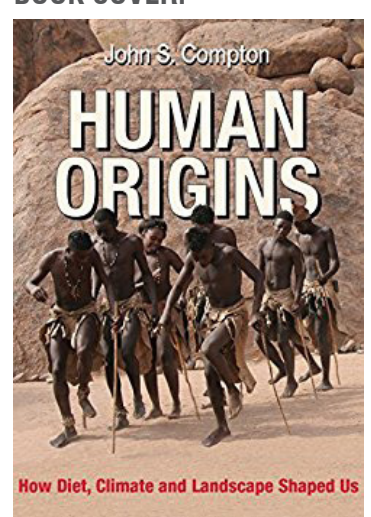

AUTHOR:

John S. Compton

ISBN:

9780620696036 (ebook)

\section{PUBLISHER:}

Earthspun Books, Cape Town; ZAR75

PUBLISHED:

2016

\section{REVIEWER:}

Emily Holt

\section{AFFILIATION:}

Previous: College of Science and Engineering, James Cook University, Cairns, Australia

Current: Department of Infectious Disease, Alfred Health, Melbourne, Australia

\section{EMAIL:}

emily.holt@my.jcu.edu.au

\section{HOW TO CITE:}

Holt $E$. The complex origin of modern humans. S Afr $J$ Sci. 2017:113(9/10), Art. \#a0233, 2 pages. http://dx.doi. org/10.17159/sajs.2017/a0233

(C) 2017. The Author(s). Published under a Creative Commons Attribution Licence.
Human origins and the factors influencing our evolution are fundamental to understanding our past, reflecting on our present, and determining our future. The seminal work of Charles Darwin provided evidence for a natural process of evolution, and an explanation for the immense abundance of species on earth; it also opened the way for study on the origin of humans.

In his book Human Origins: How Diet, Climate and Landscape Shaped Us, Compton includes a vast amount of information in support of the influence of the environment on the formation of life and evolutionary processes, as well as the associated physical traits, diet and behaviour of species. Tied to these are detailed discussions on DNA and genetics, hominin evolution and the most likely area in Africa that was the birthplace of modern humans (Homo sapiens). Compton also delivers a sobering reminder of the effects modern humans have had, and continue to have, on the environment, and where we may be in the future.

This book is comprehensive and the content is reflective of the author's more than 20 years in academia, knowledge of geology and location within South Africa. Compton covers a large range of subject matters in an easily understandable manner, and the arguments, explanations and evidence are well presented. The addition of figures, including photographs of fossils, further assist the reader by providing appropriate visual examples of explanations in the text. However, there are a number of areas where expansion of the subject matter would have provided clarity, and ensured that the reader is aware of the different interpretations of anthropological, archaeological and palaeoclimate studies. Human Origins is a great starting point for understanding evolution and the complexity of climate-environment-animal-human interactions; it should also entice the reader to expand their knowledge on the topics covered in the book.

Starting at the very beginning, Compton guides us from the Big Bang to the evolution of life on earth. The first two chapters are engaging, with a description of earth's formation, early geological and atmospheric processes, the appearance of life, and the perilous journey of evolution. Devoting these first chapters to pre-human origins is effective, as this background information is fundamental to understanding the evolutionary processes discussed later in the text.

The majority of Human Origins is dedicated to the journey from our earliest ancestors to Homo sapiens as the dominant species living on earth today. Compton delves into the myriad factors that are posited to have influenced the development of modern humans, including those stipulated in the title (diet, climate and landscape), as well as social and behavioural aspects. There is a particular focus on Africa, and for good reason: Africa has fossils of multiple hominin species, in addition to archaeological artefacts that demonstrate the adoption and progression of fire and tool use, as well as cultural development. Furthermore, Africa is, by consensus and supported by genetic studies, considered to be the birthplace of $H$. sapiens.

It is difficult to amalgamate large amounts of scientific information and Compton must be commended for doing so. However, there are areas in Human Origins that would benefit from the addition of more information; here follow some examples. Dating is vital for matching climate, environment and fossils, and placing them at key points in time; yet, there is a curious lack of discussion about the methods used to provide the dates presented. Also noted is the brief coverage of East Africa in the context of the discussion on isolation hypothesis/allopatric speciation, which is proposed as a major driver in $\mathrm{H}$. sapiens emergence. While it is certainly true that the complexity of climate and environmental variation in Central and East Africa during glacial/interglacial periods makes the interpretation of isolated areas here difficult (which Compton acknowledges), the important hominin fossil sites in East Africa warrant further examination. Finally, when discussing modern human expansion, Compton mentions that Aboriginal Australians, soon after their arrival in Australia, played an exclusive role in altering vegetation type and causing megafauna extinction. I submit that ongoing shifts in climate, in addition to natural fires, have not been discounted as significant influences on the Australian environment and biota at that time.

As a final point, evidence and scientific consensus on modern human origin and ancestral lineage is in constant flux. With each new fossil discovery and improvement in dating methods, the proposed phylogenetic tree changes; Compton himself makes the comment that interpretations are likely to change markedly over time. It is unfortunate that progress is somewhat hindered by a lack of adequately preserved fossils from key areas in Africa. Nevertheless, recently reported studies have included some momentous discoveries. Fossils from Jebel Irhoud in northern Africa are now reported to be the oldest known fossils of what is identified to be early $\mathrm{H}$. sapiens, with a stated age of over 300000 years. ${ }^{1,2}$ Additionally, dating of the Homo naledi fossils from Rising Star Cave in South Africa indicates that these fossils are much younger than first thought, with an age range of $\sim 230000$ to $\sim 330000$ years. ${ }^{3,4}$ These findings will undoubtedly lead to further discussion and scholarly debate on hominin interactions, lineage and movement within, and out of, Africa.

I would certainly recommend Human Origins as a valuable text to readers with an interest in, or studying, the origins of life, evolutionary processes, hominin phylogeny, and the history and impacts of $H$. sapiens. Compton has written a book with easily understandable content, which introduces the reader to vital concepts and hypotheses in evolution, and the importance of environmental factors on human origins. The reader should also take note of the suggested readings at the end of the book - there is a list of material to challenge even the most intrepid scholar - to continue their journey to understanding the many factors leading to us as the only remaining species of the Homo lineage. 


\section{References}

1. Hublin J-J, Ben-Ncer A, Bailey SE, Freidline SE, Neubauer S, Skinner MM, et al. New fossils from Jebel Irhoud, Morocco and the pan-African origin of Homo sapiens. Nature. 2017;546:289-292. http://dx.doi.org/10.1038/nature22336

2. Richter $D$, Grün $R$, Joannes-Boyau R, Steele TE, Amani F, Rué M, et al. The age of the hominin fossils from Jebel Irhoud, Morocco, and the origins of the Middle Stone Age. Nature. 2017;546:293-296. http://dx.doi.org/10.1038/nature22335
3. Dirks PHGM, Roberts EM, Hilbert-Wolf H, Kramers JD, Hawks J, Dosseto A, et al. The age of Homo naledi and associated sediments in the Rising Star Cave, South Africa. eLife. 2017;6, e24231, 59 pages. https://doi. org/10.7554/eLife.24231

4. Hawks J, Elliott M, Schmid P, Churchill SE, Ruiter DJd, Roberts EM, et al. New fossil remains of Homo naledi from the Lesedi Chamber, South Africa. eLife. 2017;6, e24232, 63 pages. https://doi.org/10.7554/eLife.24232 